\title{
Improvements in Body Composition after 4 Years of Growth Hormone Treatment in Adult-Onset Hypopituitarism Compared to Age-Matched Controls
}

\author{
Mark R. Postma ${ }^{a}$ André P. van Beek ${ }^{a}$ Peter J. Jönsson ${ }^{b}$ \\ Christa C. van Bunderen ${ }^{c}$ Madeleine L. Drent ${ }^{c}$ Anders F. Mattsson $^{b}$ \\ Cecilia Camacho-Hubner ${ }^{d}$ \\ a Department of Endocrinology, University Medical Center Groningen, University of Groningen, Groningen, \\ The Netherlands; ${ }^{b}$ Pfizer Endocrine Care, Pfizer Inc., Sollentuna, Sweden; ' Department of Internal Medicine,

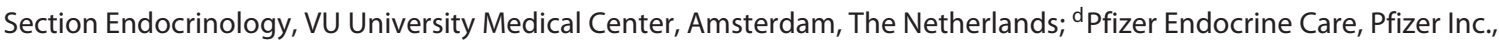 \\ New York, NY, USA
}

\section{Keywords}

Growth hormone replacement · Hypopituitarism · Body composition · BMI · Waist

\begin{abstract}
Background/Aims: It is unknown whether long-term growth hormone replacement therapy (GHRT) affects body composition in an age- or sex-dependent manner. We aimed to study the effects of 4 years of GHRT on body composition in a large cohort of patients with hypopituitarism compared to a reference population matched by age and sex. Methods: A total of $964 \mathrm{GH}$-deficient adults from KIMS (Pfizer International Metabolic Database) with adult-onset hypopituitarism, adequately replaced with all pituitary hormones except for $\mathrm{GH}$ at baseline were included. A random sample of the general population (2,301 subjects) from a similar time period was used as reference. Patients and controls were grouped by sex in 5 age cohorts of 10 years. Main outcome measures were changes in $\mathrm{BMI}$ and waist circumference after 4 years of GHRT. Results: In younger patients (28-47 years), 4 years of GHRT resulted in a BMI increase similar to that observed in the reference population, but older patients
\end{abstract}

(48-67 years) had significantly less BMI increase than agematched healthy controls. Significant differences were seen in waist circumference in patients of all age cohorts who showed virtually no change after 4 years of GHRT compared to approximately $4 \mathrm{~cm}$ of increase in the reference population. Conclusion: Four years of GHRT resulted in improvements in BMI and waist circumference in patients with adultonset hypopituitarism compared to age-matched controls observed during the same follow-up time. Despite these beneficial effects on body composition, BMI and waist circumference remained higher in patients on GHRT compared to healthy controls.

(c) 2019 The Author(s)

Published by S. Karger AG, Basel

\section{Introduction}

Advancing age is associated with increased body fat and cardiovascular risk factors $[1,2]$. Prior research has shown that patients with hypopituitarism have more body fat than age-matched controls, especially at a younger age [3]. The beneficial effects of growth hormone (GH) replacement therapy (GHRT) on body composition in

\begin{tabular}{|c|c|}
\hline KARGER & $\begin{array}{l}\text { (c) } 2019 \text { The Author(s) } \\
\text { Published by S. Karger AG, Basel }\end{array}$ \\
\hline $\begin{array}{l}\text { E-Mail karger@karger.com } \\
\text { www.karger.com/nen }\end{array}$ & $\begin{array}{l}\text { This article is licensed under the Creative Commons Attribution- } \\
\text { NonCommercial-NoDerivatives } 4.0 \text { International License (CC BY- } \\
\text { NC-ND) (http://www.karger.com/Services/OpenAccessLicense). } \\
\text { Usage and distribution for commercial purposes as well as any dis- } \\
\text { tribution of modified material requires written permission. }\end{array}$ \\
\hline
\end{tabular}

André P. van Beek, MD, $\mathrm{PhD}$

University Medical Center Groningen, De Brug 4.069, AA 31 PO Box 30.001

NL-9700 RB Groningen (The Netherlands)

E-Mail a.p.van.beek@umcg.nl 
these patients have been well documented [4-6]. However, analogous to GH dynamics in healthy adults, age itself may also be of influence [7]. Therefore, GHRT in advancing age may result in differential effects concerning changes in body composition and the related cardiovascular risk factors.

Few investigators have addressed this issue, and their reports invariably lack sufficient follow-up time and a proper reference population. Attanasio et al. [8] showed that in approximately 170 patients with adult-onset $\mathrm{GH}$ deficiency (GHD) 3 years of GH treatment resulted in a BMI increase of $0.5 \mathrm{~kg} / \mathrm{m}^{2}$ while the waist-hip ratio remained the same. Body fat decreased by $3 \%$ in this population. Age effects were not described. In another study in 380 patients of the KIMS population, after 1 year of GHRT a mean waist circumference decrease of $2.4 \mathrm{~cm}$ was observed, but no age or sex differences were reported and effects on BMI were not described [9]. Verhelst et al. [10] compared 209 patients with nonfunctioning pituitary adenomas on 2 years of GHRT and found beneficial effects on waist and related cardiovascular risk factors for both men and women, but not on weight and BMI. However, comparisons were made with craniopharyngioma patients and not with a reference population with normal pituitary function. Therefore, an estimation of effects on body composition compared to normal individuals could not be made. Furthermore, for estimations related to age a sufficiently large population of patients and controls is needed.

In 2006, the KIMS database (Pfizer International Metabolic Database) provided information on 11,687 patients with adult-onset GHD. Long-term follow-up data are available on the effects of GHRT but interpretation of the effects of GH may be influenced by concomitant temporal and societal changes in weight development. In order to make a proper comparison with a healthy population, a similar follow-up time in a similar time period is necessary.

Here we report data of 964 patients with adult-onset GHD who received 4 years of GHRT and compare them to a random sample of the Dutch population consisting of 2,301 healthy matched controls from the PREVEND study population (Prevention of REnal and Vascular ENd stage Disease) to study the effects of age and sex on body composition.

\section{Patients and Methods}

\section{Study Populations}

The KIMS database (Pfizer International Metabolic Database) was used to study the effects of hypopituitarism on obesity. KIMS, initiated in 1994, is a pharmaco-epidemiological multicenter sur- vey of adult hypopituitary (GH-deficient) patients treated with GHRT (Genotropin ${ }^{\circledR}$ ) [11]. All patients had adult-onset GHD, defined as a peak GH level of less than $3 \mu \mathrm{g} / \mathrm{L}$ mainly indicated by insulin-induced hypoglycemia (in 64\% of cases), but in other cases by a weaker $\mathrm{GH}$ stimulation test like the arginine (in 16\%), glucagon (in 7\%), GHRH (in 4\%) or other tests (in 9\%). Patients with acromegaly or Cushing's disease were excluded. Craniopharyngioma patients were excluded as well, since the susceptibility of these patients to develop central obesity and severely abnormal body composition due to hypothalamic damage is a potential confounder. The patient population consisted of patients with isolated GHD as well as multiple pituitary hormone deficiencies. All patients were receiving hormonal substitution therapy for pituitary deficiencies as necessary, except for GH. Patients included in this study started GHRT at entry into KIMS and received it for an average time of 4.0 years (SD 0.3 years). To exclude potential effects of age and pituitary deficiencies on linear growth, and therefore potentially confounding effects on body composition, only adult-onset patients were analyzed at least 10 years after completion of normal linear growth at baseline, i.e., from 28 years of age. Additionally, at baseline and at the 4 years' KIMS visit, data on weight, height, waist circumference, and GH dose needed to be present. With these selection criteria, a total of 964 patients with hypopituitarism were identified for inclusion in the analysis. The KIMS countries (number of participants) for the present study were Argentina (11), Austria (25), Belgium (86), Switzerland (10), Czech Republic (16), Germany (146), Denmark (14), Spain (80), United Kingdom (179), Greece (11), Hungary (12), Ireland (11), Luxembourg (1), the Netherlands (80), Sweden (264), and the United States (18).

Patients from KIMS were compared to a random sample of the Dutch population. This random sample consisted of 2,301 participants of the PREVEND study population (Prevention of REnal and Vascular ENd stage Disease). This ongoing prospective cohort study in the city of Groningen (the Netherlands) has since 1997 tracked the natural course of urinary albumin excretion and its relation to renal and cardiovascular disease. The study design and representativeness of this PREVEND random sample for the overall population has been described elsewhere [12]. For our purpose, it consists of a comparable and predominantly Northern European (Caucasian) population. Details of the study protocol can also be found at http://www.prevend.org.

Patients with unsubstituted GHD followed prospectively for 4 years were derived from KIMS and from the Dutch National Registry of Growth Hormone Treatment in Adults [13, 14].

Data are collected for KIMS at clinical visits on specially designed case record forms. The data collection process is externally monitored and audited. Demographic and clinical data related to pituitary and cardiovascular disease were used for the present analysis. In the PREVEND study, all information regarding demographics, cardiovascular and renal history, and the use of medication for diabetes, hypertension and hyperlipidemia was obtained using a checklist as described [15]. For this study, we used the population-based pharmacy prescription database IADB.nl [16]. All studies were approved by the local Medical Ethics Committees and conducted in accordance with the guidelines of the Declaration of Helsinki. All participants gave written informed consent.

\section{Stratification and Definitions}

Patients and controls were stratified by sex and age in 5 groups of 10 years from 28 years onwards. The age at which a patient en- 
Table 1. Male patient characteristics by age cohort

\begin{tabular}{|c|c|c|c|c|c|}
\hline & \multicolumn{5}{|l|}{ Age cohort } \\
\hline & $28-37$ years & $38-47$ years & $48-57$ years & $58-67$ years & $\geq 68$ years \\
\hline \multicolumn{6}{|l|}{ Diagnosis of GHD, \% } \\
\hline Pituitary adenoma & 47 & 85 & 79 & 83 & 92 \\
\hline Other causes of acquired pituitary disease & 20 & 7 & 8 & 10 & 3 \\
\hline Multiple hormonal deficiencies & 90 & 92 & 94 & 97 & 92 \\
\hline Duration of pituitary disease before GH start, years & $5.83 \pm 4.75$ & $7.32 \pm 7.56$ & $6.61 \pm 7.16$ & $6.25 \pm 6.32$ & $8.29 \pm 8.52$ \\
\hline Duration of GHD before GH start, years & $2.35 \pm 3.41$ & $1.63 \pm 2.68$ & $1.74 \pm 2.49$ & $2.11 \pm 3.49$ & $2.13 \pm 2.64$ \\
\hline \multicolumn{6}{|l|}{ Previous therapy, $\%$} \\
\hline Surgical treatment & 51 & 78 & 77 & 79 & 85 \\
\hline LH/FSH deficiency & 81 & 89 & 87 & 96 & 92 \\
\hline ADH deficiency & 27 & 27 & 21 & 16 & 18 \\
\hline \multicolumn{6}{|l|}{ GH treatment } \\
\hline IGF-I SDS baseline & $-1.63 \pm 1.24$ & $-1.66 \pm 1.46$ & $-1.27 \pm 1.68$ & $-1.06 \pm 1.41$ & $-1.85 \pm 1.61$ \\
\hline IGF-I SDS at 4 years & $0.53 \pm 1.43$ & $0.66 \pm 1.35$ & $0.98 \pm 1.04$ & $0.92 \pm 1.11$ & $0.69 \pm 1.30$ \\
\hline Normal IGF-1 (SDS -2 to 2 ) at 4 years, $\%$ & 88 & 86 & 85 & 81 & 82 \\
\hline Normal IGF-1 (SDS -1 to 1 ) at 4 years, $\%$ & 42 & 37 & 50 & 45 & 59 \\
\hline $\mathrm{GH}$ dose at 4 years & $0.43 \pm 0.23$ & $0.39 \pm 0.23$ & $0.33 \pm 0.19$ & $0.34 \pm 0.24$ & $0.27 \pm 0.10$ \\
\hline
\end{tabular}

Data are given as absolute numbers or percentages and mean \pm standard deviation. GHD, growth hormone deficiency.

tered KIMS or at which a control in the PREVEND study completed the baseline visit was chosen for stratification. Thus, a complete data set together with anthropometric measures and laboratory determinations for both studies was guaranteed. A provisional diagnosis of diabetes was defined on a single fasting plasma glucose level of $7.0 \mathrm{mmol} / \mathrm{L}$ or higher according to the American Diabetes Association criteria [17] or the use of antidiabetic drugs. The Seventh Report of the Joint Committee on Prevention, Detection, Evaluation, and Treatment of High Blood Pressure (JNC 7) was used to define hypertension, i.e., a systolic blood pressure of more than $140 \mathrm{~mm} \mathrm{Hg}$ or a diastolic blood pressure more than $90 \mathrm{~mm}$ $\mathrm{Hg}$ or the use of antihypertensives [18].

\section{Anthropometric Measures}

Height was measured with an accuracy of $0.5 \mathrm{~cm}$ and weight (in kilograms) to one decimal place. BMI was calculated from the formula: weight/height squared (kilograms per square meter). Waist circumference was measured in the supine position midway between the iliac crest and the lowest level of the thorax and hip as the maximal circumference. Blood pressure measurements in KIMS were standard office registrations. In the PREVEND population, blood pressure was measured with an automated device (Dinamap XL Model 9300; Johnson and Johnson Medical, Tampa, FL, USA).

Age-Dependent Effects of GH

Replacement on Body Composition

\section{Laboratory Measurements for the KIMS Population}

Measurements of serum total cholesterol [19], high-density lipoprotein (HDL) cholesterol [20], and triglycerides [21] were performed by standard methods according to the KIMS protocol. Lipids were measured centrally and serum low-density lipoprotein (LDL) cholesterol was calculated using the Friedewald formula [22]. Serum insulin-like growth factor I (IGF-I) was determined by radioimmunoassay after acid-ethanol precipitation of the binding proteins (Nichols Institute Diagnostics, San Juan Capistrano, CA, USA) until November 2002. Then a chemiluminescence immunoassay (Nichols Advantage ${ }^{\circledR}$ System) was introduced [23]. IGF-I results are expressed as standard deviation scores. All above-mentioned measurements were performed in a central laboratory. Glucose concentrations were measured in local participating centers. Whole blood concentrations were transformed to plasma values using an internally validated correction factor [24]. All measurements including glucose were determined in fasting samples.

\section{Laboratory Measurements for the PREVEND Population}

HDL cholesterol was measured with a homogeneous method (direct, HDl, Aeroset ${ }^{\mathrm{TM}}$ System, Abbott Laboratories, Abbott Park, USA). Triglycerides were measured enzymatically. Total cholesterol and plasma glucose were assessed using Kodak Ektachem dry chemistry (Eastman Kodak, Rochester, NY, USA) [15]. LDL cholesterol was calculated using the Friedewald formula [22]. Follow-up mea- 
Table 2. Female patient characteristics by age cohort

\begin{tabular}{|c|c|c|c|c|c|}
\hline & \multicolumn{5}{|l|}{ Age cohort } \\
\hline & $28-37$ years & $38-47$ years & $48-57$ years & $58-67$ years & $\geq 68$ years \\
\hline \multicolumn{6}{|l|}{ Diagnosis of GHD, \% } \\
\hline Pituitary adenoma & 47 & 62 & 55 & 76 & 67 \\
\hline Other causes of acquired pituitary disease & 31 & 22 & 26 & 10 & 10 \\
\hline Multiple hormonal deficiencies & 78 & 90 & 92 & 95 & 95 \\
\hline Duration of pituitary disease before GH start, years & $4.75 \pm 4.27$ & $8.66 \pm 7.48$ & $9.83 \pm 9.25$ & $11.24 \pm 11.00$ & $10.22 \pm 12.04$ \\
\hline Duration of GHD before GH start, years & $1.44 \pm 2.09$ & $2.25 \pm 4.18$ & $2.81 \pm 4.64$ & $1.63 \pm 1.98$ & $2.53 \pm 5.82$ \\
\hline \multicolumn{6}{|l|}{ Previous therapy, \% } \\
\hline Surgical treatment & 51 & 61 & 60 & 66 & 57 \\
\hline LH/FSH deficiency & 68 & 75 & 75 & 77 & 52 \\
\hline ADH deficiency & 18 & 26 & 24 & 15 & 14 \\
\hline \multicolumn{6}{|l|}{$\mathrm{GH}$ treatment } \\
\hline IGF-I SDS baseline & $-2.52 \pm 1.52$ & $-2.10 \pm 1.66$ & $-2.04 \pm 1.76$ & $-1.82 \pm 1.31$ & $-2.14 \pm 0.90$ \\
\hline IGF-I SDS at 4 years & $0.17 \pm 1.51$ & $0.36 \pm 1.18$ & $0.42 \pm 1.18$ & $0.89 \pm 0.91$ & $1.36 \pm 0.87$ \\
\hline Normal IGF-1 (SDS -2 to 2 ) at 4 years, $\%$ & 87 & 89 & 90 & 88 & 79 \\
\hline Normal IGF-1 (SDS -1 to 1 ) at 4 years, $\%$ & 49 & 54 & 60 & 47 & 32 \\
\hline $\mathrm{GH}$ dose at 4 years & $0.62 \pm 0.32$ & $0.52 \pm 0.28$ & $0.44 \pm 0.26$ & $0.40 \pm 0.19$ & $0.30 \pm 0.15$ \\
\hline
\end{tabular}

Data are given as absolute numbers or percentages and mean \pm standard deviation. GHD, growth hormone deficiency.

surements of HDL cholesterol and triglycerides were not available at 4 years for the PREVEND population. All measurements including plasma glucose were determined in fasting samples.

\section{Statistics}

All calculations were performed with SAS (version 9.4, SAS Institute Inc., Cary, NC, USA) or SPSS 22.0 (SPSS, Chicago, IL, USA) software. Data are reported as mean \pm SD. Males and females were analyzed separately to exclude a sex effect. For assessment of significance of mean differences between the control population and the patients with adult-onset hypopituitarism, unpaired Student's $t$ tests were performed. If variances were tested unequally between populations, Satterthwaite's correction was applied. Comparisons of proportions were performed using the $\chi^{2}$ test. A two-sided $p$ value $<0.05$ was considered to be significant.

\section{Results}

\section{Baseline Characteristics}

Baseline characteristics of the GH-deficient patients per age and sex group are shown in Tables 1 and 2. The most prevalent diagnosis was pituitary adenoma. The majority of patients received surgery as primary treatment and had multiple hormonal deficiencies. Anterior pituitary deficiencies were significantly less common in the youngest age groups (28-37 years), except for LH/ FSH deficiency in females, which was less common in the oldest age group ( $>68$ years). ADH deficiency was less common in patients aged $>58$ years. Male patients had more ACTH and LH/FSH deficiency than females. The differences between the age and sex groups in prevalence of pituitary deficiencies after 4 years of GHRT were similar to those at baseline (data not shown).

All patients with TSH and ACTH deficiency received adequate hormonal substitution at baseline and after 4 years of GHRT. More than $95 \%$ of LH/FSH-deficient males were treated with testosterone both at baseline and after 4 years of GHRT. No significant differences were found in treatment with testosterone between the different age groups of male patients (data not shown).

The mean duration of GHD before the start of GHRT was not significantly different between sexes and between age groups. Patients were treated with GH with daily in- 
Table 3. Baseline anthropometric measures and cardiovascular risk factors in male patients and controls

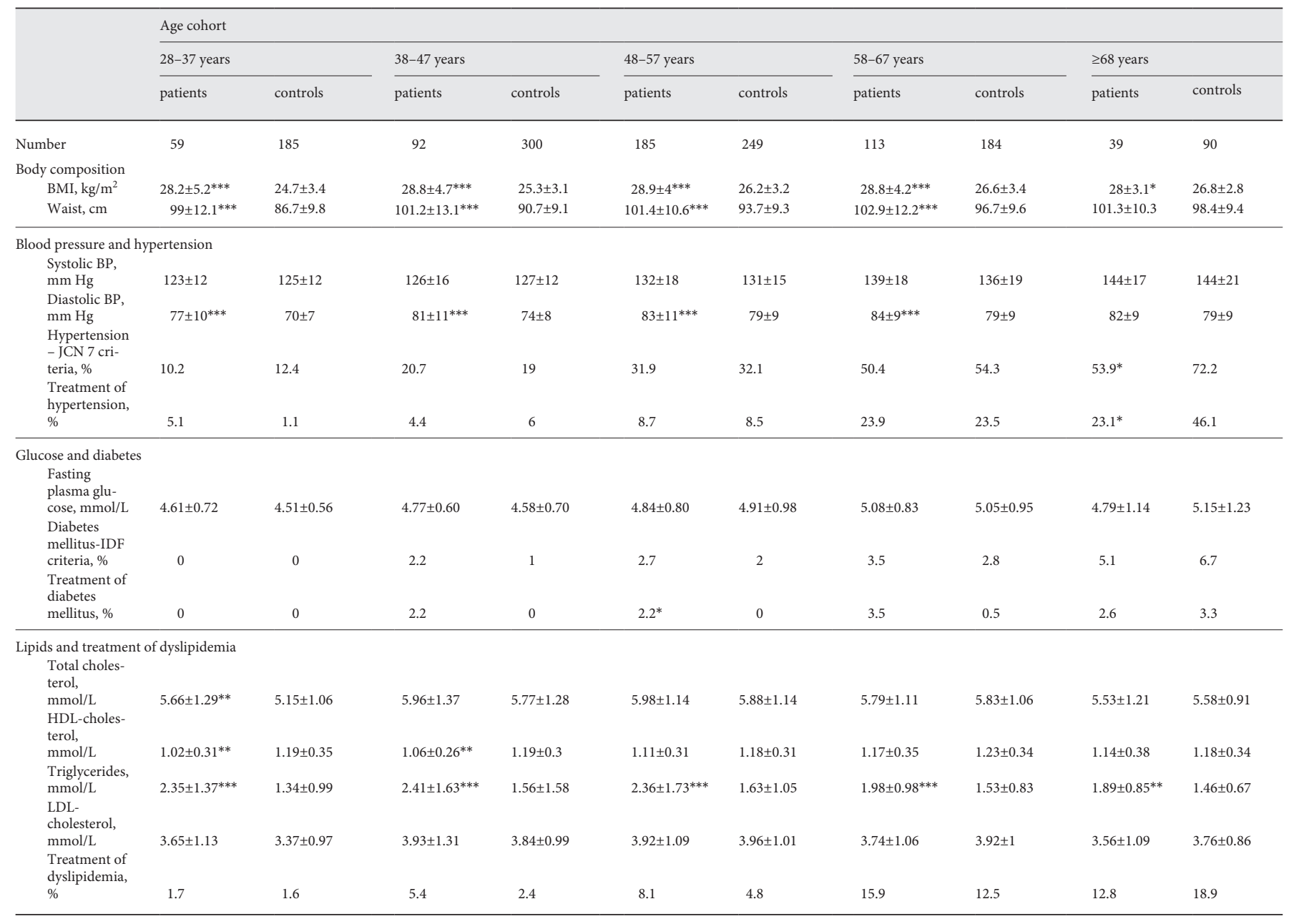

Data are given as mean \pm SD. ${ }^{*} p<0.05,{ }^{* *} p<0.01,{ }^{* * *} \mathrm{p}<0.001$ (patients vs. controls of similar age cohorts). BP, blood pressure.

jections (s.c.), which resulted in a mean IGF-I SDS after 4 years of GHRT of 0.5-1.0 in men and 0.2-1.3 in women. The mean GH dose after 4 years of GHRT was $0.3-0.4$ $\mathrm{mg} /$ day for men and $0.3-0.6 \mathrm{mg} /$ day for women, with higher doses at younger age.

Treatment of Cardiovascular Risk Factors at Baseline Hypertension and its treatment was more common in the oldest patients ( $>68$ years) and in the youngest female patients (28-37 years). Diabetes and its treatment was more common in patients aged $48-57$ years and in the youngest group of female patients (28-37 years). Treatment of dyslipidemia was more common in female patients aged $28-57$ years.

Tables 3 and 4 show anthropometric measures and cardiovascular risk factors at baseline in different age co- horts of patients and controls for males and females, respectively. The same measures after 4 years of GHRT are shown in online supplementary Tables 1 and 2 (see www. karger.com/doi/10.1159/000499430 for all online suppl. material). The effects of 4 years of GHRT on BMI, waist circumference, and cardiovascular risk factors in patients compared to age-matched healthy controls are detailed in online supplementary Table 3 and depicted in Figure 1 for the main outcome measures.

\section{Effects of 4 Years of GHRT \\ BMI}

At baseline, patients had a significantly higher BMI than controls in all age groups except in females $>68$ years. In younger patients ( $<48$ years) and in the oldest age group ( $>68$ years) 4 years of GHRT resulted in a BMI 
Table 4. Baseline anthropometric measures and cardiovascular risk factors in female patients and controls

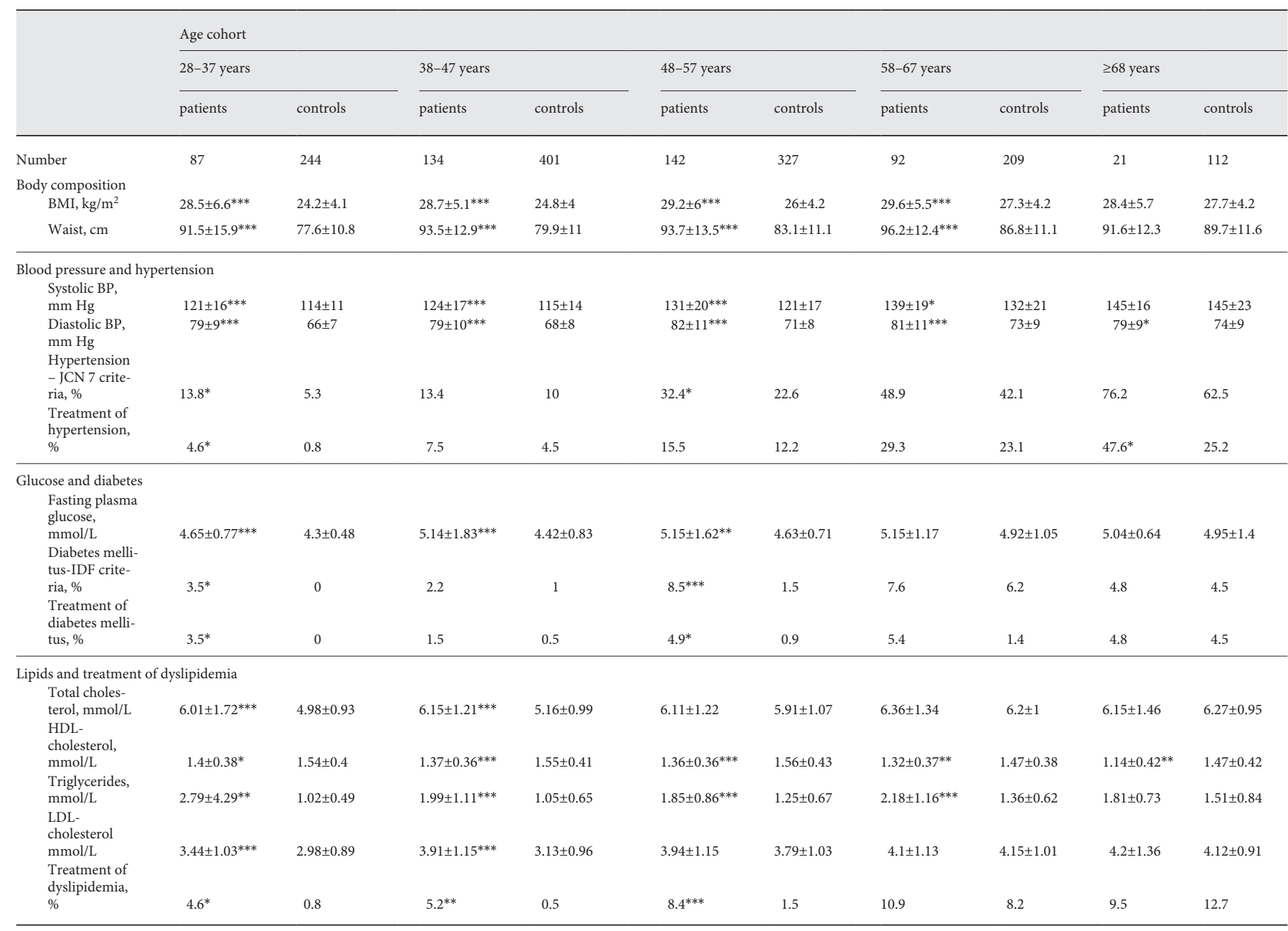

Data are given as mean \pm SD. ${ }^{*} p<0.05,{ }^{* *} p<0.01,{ }^{* * *} p<0.001$ (patients vs. controls of similar age cohorts). BP, blood pressure.

increase not significantly different from the age-dependent BMI increase observed in the reference population. However, patients aged 48-67 years had significantly less BMI increase than age-matched healthy controls.

\section{Waist Circumference}

At baseline, patients had a significantly higher waist circumference in all age groups except in the oldest group ( $>68$ years). Highly significant differences were seen for changes in waist circumference for both males and females except in the oldest age groups. Patients in all age groups showed virtually no change after 4 years of GHRT, compared to an increase of approximately $4 \mathrm{~cm}$ in the reference population.

\section{Systolic Blood Pressure}

At baseline, systolic blood pressure in males was similar for all patient and control groups. In contrast to males, female patients had a significantly higher systolic blood pressure than controls in all but the oldest age group (i.e., $>68$ years). After 4 years of GHRT, a larger increase was observed in male patients aged $28-57$ years and in female patients aged $28-37$ years and $>68$ years.

\section{Diastolic Blood Pressure}

At baseline, diastolic blood pressure was significantly higher in patients compared to controls in all age groups, except for males in the age group $>68$ years. It decreased significantly compared to controls only in female patients aged $48-57$ years. 
Fig. 1. BMI (upper panels) and waist circumference (lower panels) in men (left panels) and women (right panels) belonging to 5 age cohorts. Data represent the mean for patients with adult-onset $\mathrm{GH}$ deficiency (circles) and for controls (squares) at baseline (black symbols and continuous line) and after 4 years of follow-up (white symbols and dashed line). Increases for BMI and waist circumference are depicted in yellow in controls after 4 years of followup. In dark blue increases and in blue lines decreases for BMI and waist circumference are depicted in patients after 4 years of treatment with GH.

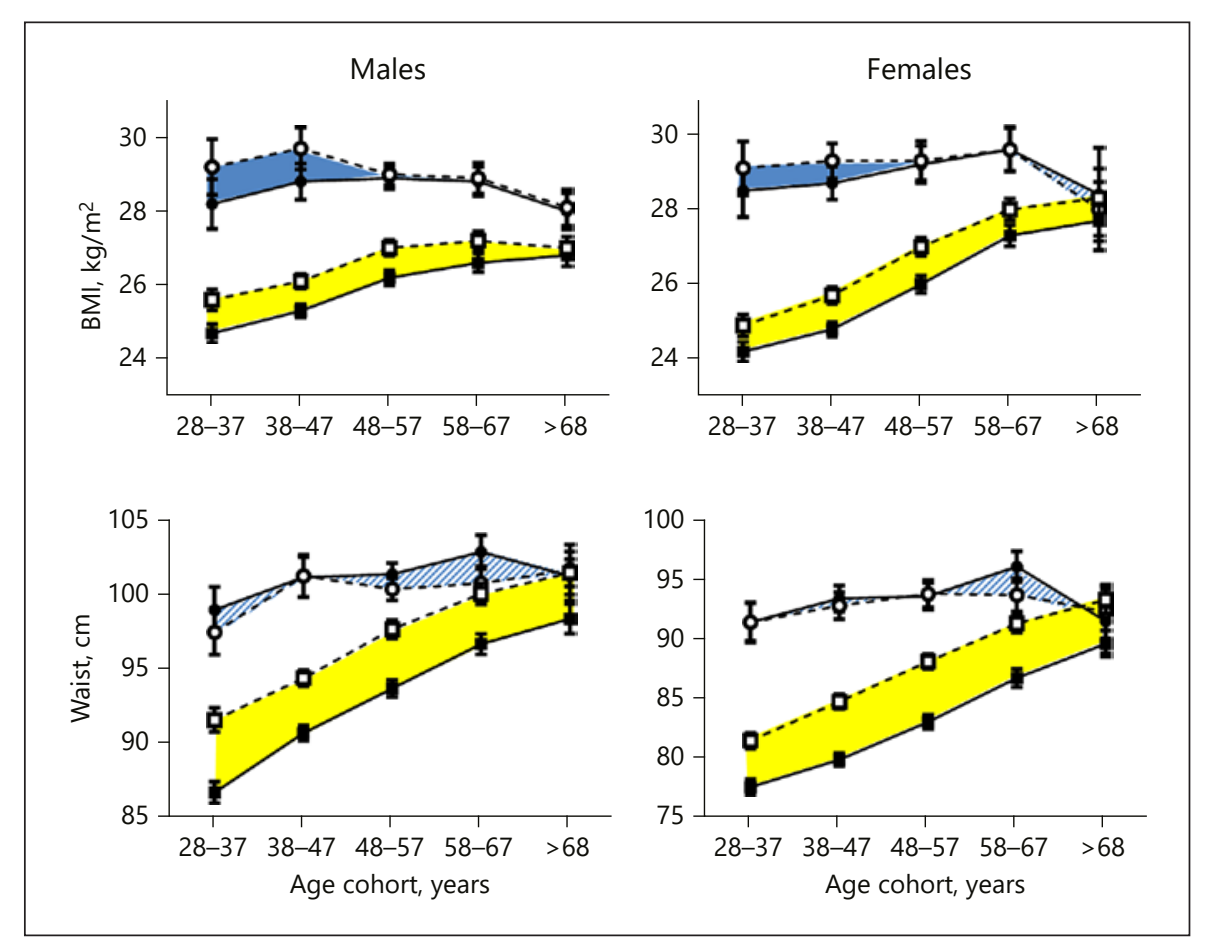

Fasting Glucose and Diabetes Mellitus

At baseline, glucose concentrations were significantly higher in female patients aged $28-57$ years. In total, 39 patients (4.0\%) and 64 controls (2.8\%) developed diabetes mellitus during follow-up. No significant differences in effect of 4 years of GHRT were observed between patients and controls.

\section{Total Cholesterol}

At baseline, total cholesterol was significantly higher in patients compared to controls in males aged 28-37 years and in females aged 28-47 years. After 4 years of GHRT, a significantly larger decrease in total cholesterol in male patients aged $28-37$ and $48-57$ years and in female patients aged $28-67$ years was observed.

\section{Overall Group Comparisons with Patients after 4 \\ Years of Unsubstituted GHD}

A total of 78 patients with unsubstituted GHD who were prospectively followed were identified. Baseline characteristics are shown in online supplementary Table 4. Patients with unsubstituted GHD were comparable to GHRT patients in terms of diagnosis related to GHD, previous therapy and pituitary hormone deficiencies. However, they were slightly older, had a longer duration of pituitary disease, and had lower IGF-1 SD scores after 4 years of follow-up.

Age-Dependent Effects of GH

Replacement on Body Composition
Data for all age groups combined from the largest population $(n=60)$ showed that the increase in waist circumference was intermediate between patients after 4 years of GHRT and controls (online suppl. Table 5), while BMI remained similar. The small group of control patients from the Dutch National Registry of Growth Hormone Treatment in Adults showed a BMI increase similar to that observed in healthy controls. After 4 years of followup, there was more treatment of diabetes mellitus (6.7\%) and dyslipidemia (25\%) in unsubstituted GH-deficient patients from the KIMS database than in the GHRT patients and healthy controls, but treatment of hypertension $(22 \%)$ was similar to the GHRT patients.

\section{Discussion}

Four years of GHRT resulted in improvements in BMI and waist circumference in patients with adult-onset hypopituitarism compared to age-matched controls observed during the same follow-up time. Despite these beneficial effects on body composition, BMI and waist circumference remained higher in patients on GHRT compared to healthy controls and cardiovascular risk factors did not clearly improve.

This is the largest study on the effects of GHRT that includes a reference population matched by age and sex.

Neuroendocrinology 2019;109:131-140 
Our study contained two populations from well-known studies, the KIMS study and the PREVEND study. Both studies are characterized by meticulous data acquisition, which is achieved for KIMS by monitoring and auditing systems. PREVEND participants completed a questionnaire at baseline regarding demographics, cardiovascular and renal history and the use of medication for diabetes, hypertension or hyperlipidemia $[15,25]$. In addition, it used the population-based pharmacy prescription database IADB.nl [16]. Combination of these sources resulted in a high-quality registration of prescribed medication. Both studies are also from the same period thereby taking into account normal social and temporal trends in weight development.

We found no differences between men and women after 4 years of GHRT. This is in agreement with findings of others [8-10]. However, in two studies, a greater responsiveness of IGF-I to GHRT in men compared to women with GHD was found to be accompanied by more pronounced changes in body composition, specifically a greater loss of fat mass and greater increments in fat-free mass [26, 27]. Furthermore, in two uncontrolled studies, a weight regain above baseline was found after 2-5 years of GHRT $[28,29]$. In accordance with these latter findings, we found a BMI increase after 4 years in most of the age cohorts. The weight gain without an increase in waist circumference suggests increase in fat-free mass or augmentation of the subcutaneous compartment. Interestingly, this effect was age dependent. The lack of BMI increase in the elderly from age 48 and older may well reflect an impairment in increase in fat-free mass, i.e., muscle mass. This in fact coincides with the observation that BMI is not increasing in males after 48 years of age in a healthy population [3].

Despite the beneficial effects of GHRT on body composition, cardiovascular risk factors did not clearly improve. Higher blood pressure and glucose levels as well as more treatment for dyslipidemia, hypertension and diabetes were found in the patient groups. Most likely, a treatment bias is present contributing to these differences. It is well known that risk for diabetes or cardiovascular disease is increased in patients with pituitary disease [3032], and accordingly, screening and treatment is initiated. Total cholesterol levels showed either a trend towards a decrease or a significantly larger decrease in patients compared to controls in all age groups after 4 years of GHRT. Of note were the large differences in triglycerides at baseline, which were higher in patients compared to controls in all age groups. Previous KIMS studies have demonstrated that triglyceride levels remain unaffected during GHRT, whereas LDL cholesterol is the component that decreases most and that contributes most to the decrease in total cholesterol $[10,33,34]$.

Our study is prone to several shortcomings. First, although appropriate for a large epidemiologic study, the use of BMI and waist circumference alone is not adequate to characterize body composition. Unfortunately, data on fat mass, fat-free mass, and bone mass are not available in KIMS and PREVEND. Secondly, to demonstrate the anthropometric age effects of GHRT, a study design with a large group of patients paired for age and sex with GHD but without treatment would be preferable. To the best of our knowledge, this is the first description of long-term follow-up in two populations with unsubstituted GHD, albeit that both populations are relatively small. The results suggest that patients with unsubstituted GHD show an increase in adiposity (measured as waist circumference), but overall weight remained constant. The data also suggest that there is no undertreatment for cardiovascular risk factors in these populations. Although these data represent a unique sample and are of special interest, interpretation should be done carefully because of potential confounding factors. We therefore limited the presentation of these data to descriptive statistics.

The Dutch population served as a control population. In general, the Dutch population is one of the leanest in Europe, theoretically making them less suitable for comparison. However, a recent prevalence study showed the Dutch population matches well with other northern European countries in terms of obesity and cardiometabolic health [35]. Nevertheless, the authors are aware that the PREVEND study population is likely not a good choice as a control to US, Latin American and Southern European populations, which are generally more obese. Therefore, a sensitivity analysis was performed for the main outcome measures of BMI and waist circumference, in which 120 patients with hypopituitarism not well represented in the control group were excluded. It can be concluded from this analysis, that this study's major findings are robust to the exclusion of these patients (data not shown). Furthermore, a bias in the selection of patients for GHRT may be present, for instance in the exclusion of patients with (pre)diabetes. Additionally, patients with a lack of beneficial effects may have stopped early during treatment. Therefore, only successfully treated patients may be present in our study population.

Another source of systematic errors may be present in the blood pressure measurements. The PREVEND study used an automated device (Dinamap XL model 9300), whereas in KIMS, standard office blood pressure mea- 
surements were recorded. Automated devices are known to result in slightly different blood pressure registrations $[36,37]$. Since methods in both studies have remained unchanged, it is unlikely for this difference in method of blood pressure measurements to affect differences in blood pressure over time. Also, waist circumference measurements as used in this study are prone to systematic errors due to interobserver bias. Laboratory measurements were also different between the two study populations, although in both studies, lipids, and in the KIMS population, IGF-I, were measured centrally, which ensured a high level of reliability within the studies. Although the standard practice of clinical chemists in a modern laboratory requires that results be reported only after validation with internal and external standards, small differences between both methods are possible.

In conclusion, 4 years of GHRT resulted in beneficial effects on body composition for all patients, but without clear associated improvements in cardiovascular risk fac- tors. The effects on waist circumference were age independent and were observed in both younger and older patients. The effects on BMI were age dependent and became only apparent after comparison with a control population matched by age.

\section{Acknowledgement}

We express our thanks to the KIMS investigators who provided the patient data. KIMS is sponsored by Pfizer.

\section{Disclosure Statement}

M.R.P. is a recipient of the Pfizer ASPIRE Young Investigator Research Award in Endocrinology. A.P.B. has received consulting fees from Pfizer and is a member of the KIMS Steering Committee. A.F.M. and C.C.-H. are full-time employees and P.J.J. was an employee of Pfizer Inc. at the time of study conduct. C.C.B. and M.L.D. have no disclosures.

\section{References}

1 Corpas E, Harman SM, Blackman MR. Human growth hormone and human aging. Endocr Rev. 1993 Feb;14(1):20-39.

2 Ettinger WH, Wahl PW, Kuller LH, Bush TL, Tracy RP, Manolio TA, et al.; The CHS Collaborative Research Group. Lipoprotein lipids in older people. Results from the Cardiovascular Health Study. Circulation. 1992 Sep 86(3):858-69.

3 van Beek AP, Wolffenbuttel BH, Runge E, Trainer PJ, Jönsson PJ, Koltowska-Häggström $M$. The pituitary gland and age-dependent regulation of body composition. J Clin Endocrinol Metab. 2010 Aug;95(8):3664-74.

4 Jørgensen JO, Pedersen SA, Thuesen L, Jørgensen J, Ingemann-Hansen T, Skakkebaek $\mathrm{NE}$, et al. Beneficial effects of growth hormone treatment in GH-deficient adults. Lancet. 1989 Jun;1(8649):1221-5.

5 Salomon F, Cuneo RC, Hesp R, Sönksen PH. The effects of treatment with recombinant human growth hormone on body composition and metabolism in adults with growth hormone deficiency. N Engl J Med. 1989 Dec; 321(26): 1797-803.

6 Jørgensen JO, Juul A. THERAPY OF ENDOCRINE DISEASE: Growth hormone replacement therapy in adults: 30 years of personal clinical experience. Eur J Endocrinol. 2018 Jul;179(1):R47-56.

7 Roelfsema F, Veldhuis JD. Growth Hormone Dynamics in Healthy Adults Are Related to Age and Sex and Strongly Dependent on Body Mass Index. Neuroendocrinology. 2016; 103(3-4):335-44.
8 Attanasio AF, Bates PC, Ho KK, Webb SM, Ross RJ, Strasburger CJ, et al.; Hypoptiuitary Control and Complications Study International Advisory Board. Human growth hormone replacement in adult hypopituitary patients: long-term effects on body composition and lipid status-3-year results from the HypoCCS Database. J Clin Endocrinol Metab. 2002 Apr;87(4):1600-6.

9 Svensson J, Finer N, Bouloux P, Bevan J, Jonsson $\mathrm{B}$, Mattsson AF, et al.; KIMS International Board. Growth hormone (GH) replacement therapy in GH deficient adults: predictors of one-year metabolic and clinical response. Growth Horm IGF Res. 2007 Feb; 17(1):67-76.

10 Verhelst J, Kendall-Taylor P, Erfurth EM, Price DA, Geffner M, Koltowska-Häggström $\mathrm{M}$, et al. Baseline characteristics and response to 2 years of growth hormone $(\mathrm{GH})$ replacement of hypopituitary patients with GH deficiency due to adult-onset craniopharyngioma in comparison with patients with nonfunctioning pituitary adenoma: data from KIMS (Pfizer International Metabolic Database). J Clin Endocrinol Metab. 2005 Aug;90(8): 4636-43.

11 Abs R, Bengtsson BA, Hernberg-Stâhl E, Monson JP, Tauber JP, Wilton P, et al. GH replacement in 1034 growth hormone deficient hypopituitary adults: demographic and clinical characteristics, dosing and safety. Clin Endocrinol (Oxf). 1999 Jun;50(6):703-13.
12 Mahmoodi BK, Gansevoort RT, Veeger NJ, Matthews AG, Navis G, Hillege HL, et al.; Prevention of Renal and Vascular End-stage Disease (PREVEND) Study Group. Microalbuminuria and risk of venous thromboembolism. JAMA. 2009 May;301(17):1790-7.

13 van Bunderen CC, van Nieuwpoort IC, Arwert LI, Heymans MW, Franken AA, Koppeschaar HP, et al. Does growth hormone replacement therapy reduce mortality in adults with growth hormone deficiency? Data from the Dutch National Registry of Growth Hormone Treatment in adults. J Clin Endocrinol Metab. 2011 Oct;96(10):3151-9.

14 van Nieuwpoort IC, van Bunderen CC, Arwert LI, Franken AA, Koppeschaar HP, van der Lelij AJ, et al. Dutch National Registry of GH Treatment in Adults: patient characteristics and diagnostic test procedures. Eur J Endocrinol. 2011 Apr;164(4):491-7.

15 Pinto-Sietsma SJ, Janssen WM, Hillege HL, Navis G, De Zeeuw D, De Jong PE. Urinary albumin excretion is associated with renal functional abnormalities in a nondiabetic population. J Am Soc Nephrol. 2000 Oct; 11(10):1882-8.

16 Schirm E, Monster TB, de Vries R, van den Berg PB, de Jong-van den Berg LT, Tobi H. How to estimate the population that is covered by community pharmacies? An evaluation of two methods using drug utilisation information. Pharmacoepidemiol Drug Saf. 2004 Mar;13(3):173-9. 
17 Expert Committee on the Diagnosis and Classification of Diabetes Mellitus. Report of the expert committee on the diagnosis and classification of diabetes mellitus. Diabetes Care. 2003 Jan;26 Suppl 1:S5-20.

18 Chobanian AV, Bakris GL, Black HR, Cushman WC, Green LA, Izzo JL Jr, et al.; National High Blood Pressure Education Program Coordinating Committee. The Seventh Report of the Joint National Committee on Prevention, Detection, Evaluation, and Treatment of High Blood Pressure: the JNC 7 report. JAMA. 2003 May;289(19):2560-72.

19 Lie RF, Schmitz JM, Pierre KJ, Gochman N. Cholesterol oxidase-based determination, by continuous-flow analysis, of total and free cholesterol in serum. Clin Chem. 1976 Oct; 22(10):1627-30.

20 Lopes-Virella MF, Stone P, Ellis S, Colwell JA. Cholesterol determination in high-density lipoproteins separated by three different methods. Clin Chem. 1977 May;23(5):882-4.

21 Fossati P, Prencipe L. Serum triglycerides determined colorimetrically with an enzyme that produces hydrogen peroxide. Clin Chem. 1982 Oct;28(10):2077-80.

22 Friedewald WT, Levy RI, Fredrickson DS. Estimation of the concentration of low-density lipoprotein cholesterol in plasma, without use of the preparative ultracentrifuge. Clin Chem. 1972 Jun; 18(6):499-502.

23 Brabant G, von zur Mühlen A, Wüster C, Ranke MB, Kratzsch J, Kiess W, et al.; German KIMS Board. Serum insulin-like growth factor I reference values for an automated chemiluminescence immunoassay system: results from a multicenter study. Horm Res. 2003;60(2):53-60.

24 Burnett RW, D'Orazio P, Fogh-Andersen N, Kuwa K, Külpmann WR, Larsson L, et al.; Scientific Division, Working Group on Selective Electrodes. IFCC recommendation on reporting results for blood glucose. Clin Chim Acta. 2001 May;307(1-2):205-9.
25 Lambers Heerspink HJ, Brantsma AH, de Zeeuw D, Bakker SJ, de Jong PE, Gansevoort RT; PREVEND Study Group. Albuminuria assessed from first-morning-void urine samples versus 24-hour urine collections as a predictor of cardiovascular morbidity and mortality. Am J Epidemiol. 2008 Oct;168(8):897905.

26 Johansson AG, Engström BE, Ljunghall S, Karlsson FA, Burman P. Gender differences in the effects of long term growth hormone (GH) treatment on bone in adults with $\mathrm{GH}$ deficiency. J Clin Endocrinol Metab. 1999 Jun;84(6):2002-7.

27 Span JP, Pieters GF, Sweep FG, Hermus AR, Smals AG. Gender differences in rhGH-induced changes in body composition in $\mathrm{GH}$ deficient adults. J Clin Endocrinol Metab. 2001 Sep;86(9):4161-5.

28 Rosenfalck AM, Maghsoudi S, Fisker S, Jørgensen JO, Christiansen JS, Hilsted J, et al. The effect of 30 months of low-dose replacement therapy with recombinant human growth hormone (rhGH) on insulin and Cpeptide kinetics, insulin secretion, insulin sensitivity, glucose effectiveness, and body composition in GH-deficient adults. J Clin Endocrinol Metab. 2000 Nov;85(11):417381.

29 Götherström G, Svensson J, Koranyi J, Alpsten $\mathrm{M}$, Bosaeus I, Bengtsson B, et al. A prospective study of 5 years of GH replacement therapy in GH-deficient adults: sustained effects on body composition, bone mass, and metabolic indices. J Clin Endocrinol Metab. 2001 Oct;86(10):4657-65.

30 Abs R, Mattsson AF, Thunander M, Verhelst J, Góth MI, Wilton P, et al. Prevalence of diabetes mellitus in 6050 hypopituitary patients with adult-onset $\mathrm{GH}$ deficiency before $\mathrm{GH}$ replacement: a KIMS analysis. Eur J Endocrinol. 2013 Feb;168(3):297-305.
31 Lombardi G, Colao A, Marzullo P, Ferone D, Longobardi S, Esposito V, et al. Is growth hormone bad for your heart? Cardiovascular impact of GH deficiency and of acromegaly. J Endocrinol. 1997 Oct;155 Suppl 1:S33-7; discussion S39.

32 Pereira AM, van Thiel SW, Lindner JR, Roelfsema F, van der Wall EE, Morreau $\mathrm{H}$, et al. Increased prevalence of regurgitant valvular heart disease in acromegaly. J Clin Endocrinol Metab. 2004 Jan;89(1):71-5.

33 Jørgensen AP, Fougner KJ, Ueland T, Gudmundsen O, Burman P, Schreiner T, et al. Favorable long-term effects of growth hormone replacement therapy on quality of life, bone metabolism, body composition and lipid levels in patients with adult-onset growth hormone deficiency. Growth Horm IGF Res. 2011 Apr;21(2):69-75.

34 Monson JP, Jönsson P, Koltowska-Häggström $\mathrm{M}$, Kourides I. Growth hormone (GH) replacement decreases serum total and LDLcholesterol in hypopituitary patients on maintenance HMG CoA reductase inhibitor (statin) therapy. Clin Endocrinol (Oxf). 2007 Oct;67(4):623-8.

35 van Vliet-Ostaptchouk JV, Nuotio ML, Slagter SN, Doiron D, Fischer K, Foco L, et al. The prevalence of metabolic syndrome and metabolically healthy obesity in Europe: a collaborative analysis of ten large cohort studies. BMC Endocr Disord. 2014 Feb 1; 14:9.

36 van Montfrans GA. Oscillometric blood pressure measurement: progress and problems. Blood Press Monit. 2001 Dec;6(6):287-90.

37 van Popele NM, Bos WJ, de Beer NA, van Der Kuip DA, Hofman A, Grobbee DE, et al. Arterial stiffness as underlying mechanism of disagreement between an oscillometric blood pressure monitor and a sphygmomanometer. Hypertension. 2000 Oct;36(4):484-8. 